\title{
Effect of Liquid versus Ice Slurry Ingestion on Core Temperature during Simulated Mining Conditions
}

\author{
Joseph Maté1, Rodney Siegel², Jacques Oosthuizen1*, Paul B. Laursen ${ }^{2,3}$, \\ Greig Watson" \\ ${ }^{1}$ School of Exercise and Health Sciences, Edith Cowan University, Joondalup, Australia \\ ${ }^{2}$ High Performance Sport New Zealand, Auckland, New Zealand \\ ${ }^{3}$ Sport Performance Research Institute New Zealand (SPRINZ), Auckland University of Technology, Auckland, \\ New Zealand \\ ${ }^{4}$ Faculty of Health Sciences, School of Human Life Sciences, University of Tasmania, Tasmania, Australia \\ Email: "j.oosthuizen@ecu.edu.au
}

Received 11 November 2014; accepted 24 January 2016; published 27 January 2016

Copyright (C) 2016 by authors and Scientific Research Publishing Inc.

This work is licensed under the Creative Commons Attribution International License (CC BY).

http://creativecommons.org/licenses/by/4.0/

(c) (i) Open Access

\section{Abstract}

Miners in Australia frequently perform physically demanding work under high ambient temperatures and humidity, often whilst wearing personal protective equipment, leading to heat-related illnesses. This study investigated effects of replacing $100 \%$ and $50 \%$ sweat losses with $5 \%$ carbohydrate liquid or ice-slurry solution on core temperature during simulated mining conditions. Five randomized treadmill trials were performed with: no fluid replacement (NF), 100\% (100 ICE) and $50 \%$ (50 ICE) sweat loss replaced with ice-slurry $\left(\sim-1^{\circ} \mathrm{C}\right)$ solution and $100 \%$ (100 LIQ) and $50 \%$ (50 LIQ) sweat loss replaced with liquid $\left(\sim+4^{\circ} \mathrm{C}\right)$ solution. Time to exhaustion was longer in 100 ICE followed by 100 LIQ, 50 ICE, 50 LIQ and NF. Change in rectal temperature was least in 100 ICE followed by 100 LIQ, 50 ICE, 50 LIQ and NF. Ingestion of ice-slurry resulted in longer time to exhaustion and slower rates of change in rectal temperature. It is recommended that ice-slurry drinks be provided to personnel to lower heat strain during hot working conditions.

\section{Keywords}

Thermoregulation, Occupational Heat Stress, Cooling Intervention, Ice Slurry

\footnotetext{
${ }^{*}$ Corresponding author.
}

How to cite this paper: Maté, J., Siegel, R., Oosthuizen, J., Laursen, P.B. and Watson, G. (2016) Effect of Liquid versus Ice Slurry Ingestion on Core Temperature during Simulated Mining Conditions. Open Journal of Preventive Medicine, 6, 21-30. http://dx.doi.org/10.4236/ojpm.2016.61002 


\section{Introduction}

Miners perform physically demanding work [1] [2] in hot [3] ambient working conditions, often with minimally exposed skin surface area. Miners must also occasionally wear personal protective equipment that encapsulates them and reduces their ability to dissipate heat through evaporative sweat [4]. Consequently, heat-related illnesses are a regular occurrence in the mining industry [5].

Current interventions used to reduce the development of a heat stress related illness in miners include: setting the upper limit on body temperature during work to $38.5^{\circ} \mathrm{C}$ [6], limiting the work time in hot ambient conditions according to heat stress indices [7] ("U.S. National Institute for Occupational Safety and Health: Criteria for a Recommended Standard - Occupational Exposure to Hot Environments (Revised); 1986. In NIOSH Criteria Documents Plus CD-ROM, Disk 2. DHHS (NIOSH) Pub. No. 97-106; NTIS Pub. No. PB-502-082. National Technical Information Service, Springfield, VA (1997) [7], improving ventilation practices [8], wearing cooling garments [9] and educating workers on the importance of fluid replacement [10]. However, despite these interventions, the incidence of heat stress related illnesses in the industrial setting remains high, particularly during the summer months [5]. Therefore, there is a need to examine alternative cooling methods.

A potential alternative intervention that is economically viable, easily implementable, and can concomitantly be used with currently in use heat management protocols, is modification of drinking practices. This method will theoretically enable workers to remain euhydrated and cool by drinking cool fluids and/or ice-slurry beverages. Research has shown that dehydration caused by sweating can impair physical and cognitive performance [11], reduce maximum voluntary contraction [12], while staying euhydrated by drinking enough fluid to offset sweat losses can attenuate increases in rectal temperature $\left(T_{r e}\right)$ [13] [14], cardiovascular strain and perceived exertion [15] during physical activity in the heat. Likewise, research has also shown that ingestion of cool versus warm fluids during exercise attenuates the rate of rise in $T_{r e}[16]$.

We speculate that ingestion of ice-slurry solutions during exercise may be more effective at cooling than liquid solutions because an ice-slurry elicits a larger heat sink due to the additional heat required to change phase from solid (ice) to liquid water, known as the "enthalpy of fusion". The potential effectiveness of consuming an ice-slurry solution during exercise was demonstrated by [17] who observed a lower $T_{r e}$ for the first 30 min of exercise when subjects consumed ice-slurry versus a liquid of equal volume and composition prior to exercise. The physiological effects of completely or partially replacing fluid loss during exercise with an ice-slurry is however unknown.

Thus, the purpose of this investigation was to compare the effects of ingesting ice-slurry versus liquid beverages on core temperature during simulated mining conditions. It was hypothesised that offsetting sweat losses and remaining euhydrated by drinking an ice-slurry beverage would attenuate rises in $T_{r e}$ and cardiovascular strain to a greater extent than drinking a cold liquid beverage.

\section{Methodology}

\subsection{Participants}

Ten healthy non-heat-acclimated Caucasian males (height $1.75 \pm 0.05 \mathrm{~m}$; age $29 \pm 5$ y; body mass $81.8 \pm 9.0 \mathrm{~kg}$; $19.2 \% \pm 3.1 \%$ body fat; $\dot{\mathrm{v}} \mathrm{O}_{2 \max } 46.4 \pm 6.0 \mathrm{ml} \cdot \mathrm{kg}^{-1} \cdot \mathrm{min}^{-1}$ ) gave written consent prior to participating in this study. Participants were volunteers from the local university population. Participants had the right to withdrawal at any point in the investigation without prejudice and were protected from any harm during by the investigators while participating. All information relating to withdrawing from the study and supervision by the investigators while the investigation was underway was included in the informed consent document signed by the volunteers. The study was approved by the Edith Cowan University Human Research Ethics Committee.

\subsection{Preliminary Measurements}

On their first visit, each subject's body mass (Model ID1; Mettler Toledo, USA) and height (Seca, USA) were measured. Adiposity was determined through Dual Energy X-ray Absorptiometry (Hologic, Hong Kong). Under ambient room conditions $\left(25.8^{\circ} \mathrm{C} \pm 2.0^{\circ} \mathrm{C}\right.$ at $\left.44.1 \% \pm 8.1 \% \mathrm{RH}\right)$ (Microtherm; Casella Measurement Ltd., UK), a modified Bruce treadmill protocol was used to determine $\dot{\mathrm{v}} \mathrm{O}_{2 \max }$ (ParvoMedics True One 2400 diagnostic system, UT). Participants ran at $0^{\circ}$ incline at $8 \mathrm{~km} \cdot \mathrm{h}^{-1}$ with increases of $2 \mathrm{~km} \cdot \mathrm{h}^{-1}$ every two minutes until $16 \mathrm{~km} \cdot \mathrm{h}^{-1}$, after which the incline was increased $2^{\circ}$ every two minutes until volitional fatigue occurred. 


\subsection{Experimental Design}

Participants visited the laboratory during the spring time on five separate occasions at approximately the same time of day with a minimum of 7 days separating each visit. All participants performed their first condition, considered the control condition (NF), without any drink ingestion. Differences between pre and post exercise nude body mass was used to estimate sweat rate and subsequent drink volumes. The remaining four randomized sessions included $100 \%$ replacement of estimated sweat losses with ice-slurry solution (100 ICE), or liquid (100 LIQ), and 50\% replacement of estimated sweat losses with ice-slurry solution (50 ICE), or liquid (50 LIQ).

\subsection{Protocol}

Upon arrival to the laboratory, urine and blood samples were collected and a rectal thermistor (Monatherm Thermistor, 400 Series; Mallinckrodt Medical, USA) was self-inserted by subjects, $10 \mathrm{~cm}$ past their external anal sphincter. Nude body mass was measured before instrumentation of skin thermistors and heart rate monitor (RS800 Polar Heart Rate Monitor, Finland). Participants then donned running shoes, cotton pants, t-shirt and mining helmet. Re-usable skin thermistors were fixed to the mid belly of the left gastrocnemius, quadriceps, biceps, and chest; using Ramanathan's equation to calculate mean skin temperature [18]. Change in body heat content was estimated by using the formula $T_{b}=\left(\right.$ body mass $\left.(\mathrm{kg}) \times 3.47 \mathrm{~kJ} \cdot \mathrm{kg}^{-1} \cdot{ }^{\circ} \mathrm{K}^{-1}\right) \times\left(0.65 \cdot \mathrm{T}_{\mathrm{re}}\right)+\left(0.35 \cdot \bar{T}_{\text {sk }}\right)$ equation.

Upon entering the climate chamber, participants were seated in an upright chair for $15 \mathrm{~min}$ prior to exercise. Exercise then commenced of walking on a treadmill at a constant workload of $\sim 290 \mathrm{~W} \cdot \mathrm{m}^{-2}\left(3.0 \mathrm{~km} \cdot \mathrm{hr}^{-1}\right.$ at an inclination of $\left.15^{\circ}\right)$. Ambient conditions were $28.3^{\circ} \mathrm{C} \pm 0.5^{\circ} \mathrm{C}, 74.2 \% \pm 4.6 \% \mathrm{RH}\left(25.9^{\circ} \mathrm{C} \pm 0.4^{\circ} \mathrm{C}\right.$ WBGT $)$ and wind speed $<0.1 \mathrm{~m} \cdot \mathrm{s}^{-1}$. This work intensity and ambient condition does not require an altered rest to work ratio for industrial standards [19].

During exercise, drinks were administered after 20 min of exercise and every 20 min thereafter. Participants were instructed to ingest fluids as quickly as was comfortably possible. Participants walked until either voluntary exhaustion, achieving a $T_{r e}$ of $39.0^{\circ} \mathrm{C}$, or $120 \mathrm{~min}$ of exercise. Immediately after the protocol termination, nude body mass, blood and urine, were reassessed in that order. This experimental protocol for randomization was selected as an extension to the work conducted by [17] and also to eliminate any possible learning effect from fluid ingestion and exercising in the heat. An outline of the experimental protocol can be seen in Figure 1.

\subsection{Urine Analysi}

Confirmation of euhydration was determined by urine osmolarity through freezing point depression (Advanced Instruments Inc, USA) $U_{o s m}<286 \mathrm{mOsm} \cdot \mathrm{kgH}_{2} \mathrm{O}^{-1}$ [20] and urinary specific gravity ( $U_{s g}$ ) (Refractometer, Nippon Optical Works, Japan) between 1.006 and 1.020 [21]. All urine analysis was performed in duplicate.

\subsection{Blood Analysis}

Participants sat upright in a chair for approximately 3 min prior to blood being drawn from the antecubital vein. Plasma osmolality $\left(P_{\text {osm }}\right)$, through freezing point depression (Advanced Instruments Inc, USA), was determined by collecting $8.5 \mathrm{ml}$ of blood into an SST heprinized tube and centrifuging (Heraeus Multifuge $3 \mathrm{~S}-\mathrm{R}$, Australia)

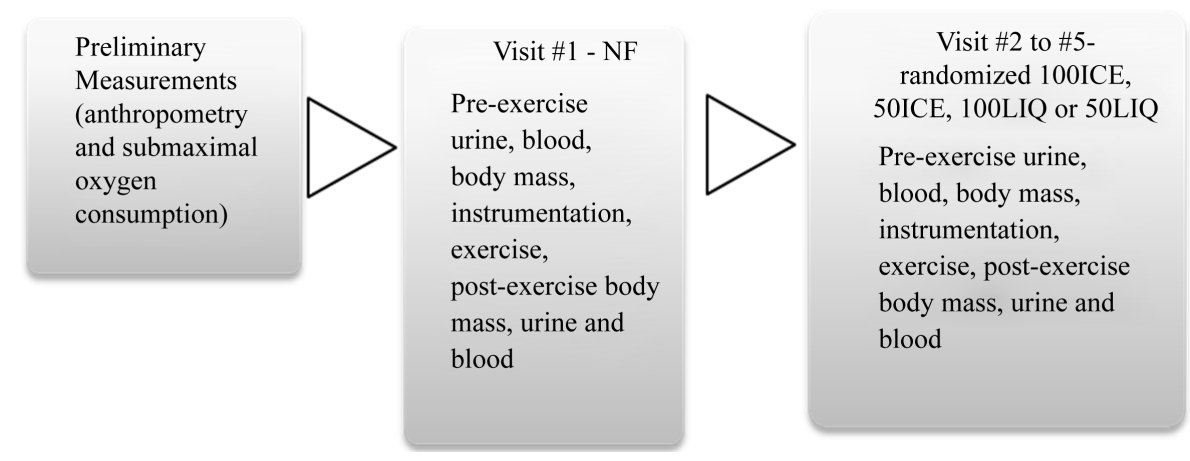

Figure 1. Flow diagram of experimental protocol. 
for $15 \mathrm{~min}$ at $3000 \mathrm{rev} \cdot \mathrm{min}^{-1}$ at $4^{\circ} \mathrm{C}$. Changes in plasma volume $(\Delta \mathrm{PV}), 8.5 \mathrm{ml}$ of blood were collected into a plain clot tube before immediately separating into 2 aliquots (30 $\mu \mathrm{L}$ each) in non-heparinized capillary tubes. Capillary tubes were spun (MED Instruments, MPW-212, Poland) at $12000 \mathrm{rev} \cdot \mathrm{min}^{-1}$ for $5 \mathrm{~min}$ at room temperature. Haemoglobin concentration was measured (Hemocue, Hb 201, Sweden) using a sample of blood (10 $\mu \mathrm{L}$ each) from the same plain clot tube. $\Delta \mathrm{PV}$ was calculated based on the method of Dill and Costil [22]. All blood analyses were preformed in duplicate, unless otherwise stated.

\subsection{Rectal and Skin Temperature and Heart Rate}

$T_{r e}$ and $\bar{T}_{s k}$ was recorded at $1 \mathrm{~Hz}$ via a data-logger (Grant Instruments, UK); 5 min averages were then calculated. Heart rate (RS800 Polar Heart Rate Monitor, Finland) was sampled every $5 \mathrm{~s}$ via telemetry and 5 min average values were calculated. A maximum $T_{r e}$ cut off of $39.0^{\circ} \mathrm{C}$ was implemented to ensure the safety of our participants.

\subsection{Ice Slurry and Liquid Composition}

Both ice-slurry $\left(\sim-1^{\circ} \mathrm{C}\right)$ and liquid drinks $\left(\sim+4^{\circ} \mathrm{C}\right)$ were composed of orange flavoured cordial (Cottee's Foods, Australia) with a $5 \%$ carbohydrate concentration. Ice-slurries were made using a slushy machine (Essential Slush Co., Australia). Drink volumes administered were determined from individual sweat loss. Participants consumed approximately $1.30 \pm 0.31 \mathrm{~L}$ for 100 ICE and $100 \mathrm{LIQ}$ conditions while $0.650 \pm 0.160 \mathrm{~L}$ was administered during 50 ICE and 50 LIQ. The temperature chosen for the liquid solution was based on typical household refrigeration temperature while the warmest temperature was used for the ice-slurry in an attempt to minimize temperature differences between drinks.

\subsection{Data Analysis}

A condition $x$ time repeated measures ANOVA was performed to identify any changes in $T_{r e}, \bar{T}_{s k}$, and HR. A 1-way ANOVA was used to examine differences in $T_{\text {lim }}$ between conditions. A urine $x$ condition repeated measures ANOVA was performed to identify any changes in $U_{o s m}, U_{s g}$, body mass, sweat rate, and PV. When differences were found, a Tukey's post hoc analysis was performed. Significance was set at $\mathrm{P}<0.05$. All analyses was performed using a statistical software program (SPSS 15.0 for windows, SPSS, Inc., Chicago, IL, USA), with values presented as means $\pm \mathrm{SD}$. A magnitude-based inference approach was also used to compare the likely benefit of each condition to one another [23] [24]. The thresholds used to provide qualitative descriptors for the magnitude of difference observed between conditions were: trivial $(<0.2)$ small $(0.2$ to 0.6$)$, moderate ( 0.6 to 1.2 ), large (1.2 to 2.0 ) and very large (>2.0). If the confidence interval spanned both positive and negative outcomes, the practical interpretation was deemed "unclear".

\section{Results}

\subsection{Hydration Status and Serum Volume}

The increases in $U_{s g}$ were observed to be different between pre and post exercise for 50 LIQ ( $\mathrm{P}=0.005$ ) (Table 1). Decreases in blood volume for 100 ICE were less than NF ( $P=0.002)$. The reduction in cell volume was greater in NF versus 50 ICE $(\mathrm{P}=0.002)$ and 50 LIQ $(\mathrm{P}=0.002)$. No differences were observed for $\% \Delta \mathrm{PV}$ between drink interventions.

\subsection{Rate of Heat Storage and Change in Rectal Temperature $\left(\Delta T_{r e}\right)$}

Rate of heat storage (Figure 2(a)) differed between NF and 100 ICE $(P=0.0001)$, 50 ICE $(P=0.004)$ and 100 LIQ; $(\mathrm{P}=0.008)$ ). The rate of heat storage between 100 ICE and $100 \mathrm{LIQ}$ were not different $\left(4.5 \pm 2.7 \mathrm{~kJ} \cdot \mathrm{min}^{-1}\right.$ vs. $5.9 \pm 3.1 \mathrm{~kJ} \cdot \mathrm{min}^{-1} ; \mathrm{P}=0.290$ ). These results were deemed unclear (mean difference $30.8 \%, 90 \% \mathrm{CI}:-14.8$ to $100.8 \%)$. Comparatively, the rate of heat storage in 100 ICE was "non-trivial or trivial to non-trivial" when compared to NF (mean difference 53.9\%, 90\% CI: -67.1 to 35.3\%), 50 ICE (mean difference $45.0 \%$, 90\% CI: -4.4 to $119.9 \%$ ) and 50 LIQ (mean difference $50.6 \%, 90 \%$ CI: 0.8 to $125.1 \%$ ).

The rate of change in $T_{r e}\left(\Delta T_{r e}\right)$ are shown in Figure 2(b), where significant differences were observed between 100 ICE and NF ( $(=0.0008), 100$ LIQ and NF ( $P=0.0015), 100$ ICE and 50 LIQ ( $=0.0131)$ and be- 
Table 1. Urine osmolality $\left(U_{o s m}\right)$, specific gravity $\left(U_{s a}\right)$, plasma osmolality $\left(P_{\text {osm }}\right)$, changes in blood volume $(\% \Delta \mathrm{BV})$, cell volume $(\% \Delta \mathrm{CV})$, plasma volume $(\% \Delta \mathrm{PV})$, and changes in body mass for each drink intervention.

\begin{tabular}{|c|c|c|c|c|c|c|c|c|}
\hline & & Uosm & Usg & $\begin{array}{l}\text { Posm } \\
(\mathrm{n}=9)\end{array}$ & $\% \Delta \mathrm{BV}$ & $\% \Delta \mathrm{CV}$ & $\% \Delta \mathrm{PV}$ & $\begin{array}{c}\Delta \text { Body Mass } \\
\text { (kg) }\end{array}$ \\
\hline \multirow{2}{*}{ No Fluid } & Pre & $163 \pm 97$ & $1.011 \pm 0.009$ & $296 \pm 7$ & & & & \\
\hline & Post & $302 \pm 178$ & $1.010 \pm 0.008$ & $294 \pm 6$ & $-4.10 \pm 2.83$ & $-6.44 \pm 1.78$ & $-2.81 \pm 5.73$ & $1.04 \pm 0.53$ \\
\hline \multirow{2}{*}{$\begin{array}{l}\text { 100\% Ice } \\
\text { Slurry }\end{array}$} & Pre & $169 \pm 75$ & $1.006 \pm 0.004$ & $291 \pm 5$ & & & & \\
\hline & Post & $239 \pm 117$ & $1.007 \pm 0.004$ & $290 \pm 5$ & $-0.11 \pm 2.68(b)$ & $-0.53 \pm 4.02$ & $0.38 \pm 4.68$ & $0.11 \pm 0.32$ (b) \\
\hline \multirow{2}{*}{$\begin{array}{c}\mathbf{5 0 \%} \text { Ice } \\
\text { Slurry }\end{array}$} & Pre & $120 \pm 58(\mathrm{a})$ & $1.005 \pm 0.005$ & $295 \pm 5$ & & & & \\
\hline & Post & $243 \pm 156$ & $1.007 \pm 0.005$ & $294 \pm 5$ & $-1.58 \pm 4.14$ & $-1.35 \pm 2.62(b)$ & $-0.58 \pm 6.88$ & $0.71 \pm 0.39$ (c) \\
\hline \multirow{2}{*}{$100 \%$ Liquid } & Pre & $156 \pm 71$ & $1.005 \pm 0.003$ & $293 \pm 3$ & & & & \\
\hline & Post & $255 \pm 194$ & $1.007 \pm 0.006$ & $292 \pm 4$ & $-2.97 \pm 3.77$ & $-3.07 \pm 1.75$ & $-2.30 \pm 6.11$ & $0.13 \pm 0.47$ (b) \\
\hline \multirow{2}{*}{$50 \%$ Liquid } & Pre & $98 \pm 64$ (a) & $1.005 \pm 0.005(\mathrm{a})$ & $293 \pm 6$ & & & & \\
\hline & Post & $385 \pm 300$ & $1.011 \pm 0.010$ & $294 \pm 6$ & $-1.89 \pm 2.45$ & $-1.43 \pm 3.50(b)$ & $-1.89 \pm 4.62$ & $0.64 \pm 0.35$ (b) \\
\hline
\end{tabular}

(a) difference between pre and post values $(\mathrm{P}<0.05)$; (b) different to No Fluid $(\mathrm{P}<0.05)$; (c) different to $100 \%$ Ice Slurry $(\mathrm{P}<0.05)$.
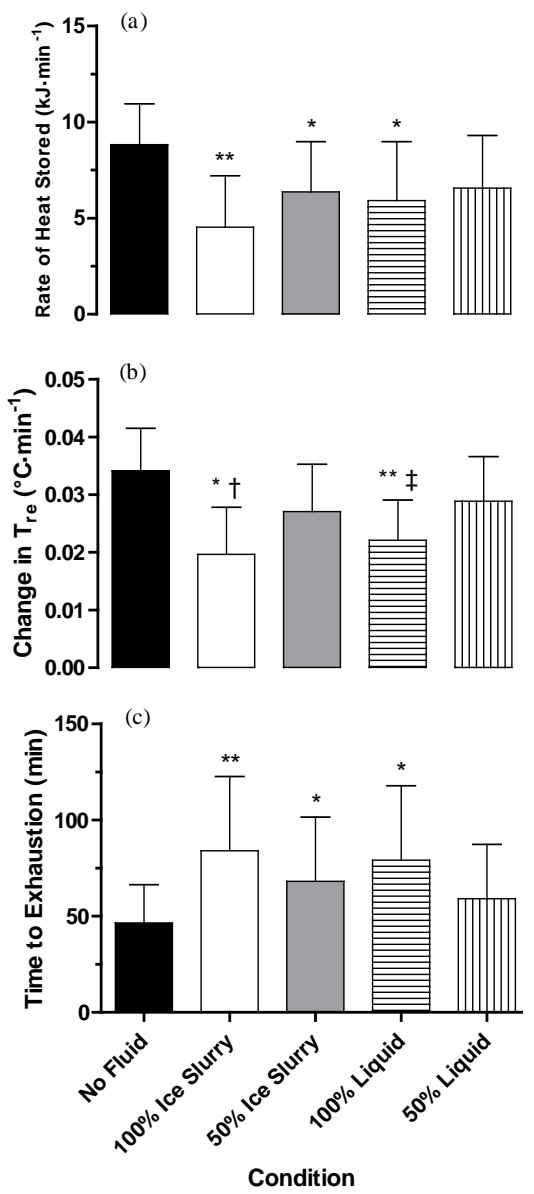

Figure 2. (a) Estimated rate of heat stored during each drink intervention. * denotes a difference of $\mathrm{P}<0.05$ from NF while ** denotes a difference of $\mathrm{P}<0.001$ from NF; (b) estimated minute changes in rectal temperature during each of the five drink interventions. * denotes a difference $\mathrm{P}<0.05$ to NF, $* *$ denotes a difference $\mathrm{P}<0.05$ to NF, † denotes a difference $\mathrm{P}<0.05$ to $50 \mathrm{LIQ}$ and $\ddagger$ denotes a difference $\mathrm{P}<0.05$ to 50 LIQ; (c) mean $( \pm \mathrm{SD})$ time to exhaustion for each drink intervention with * denoting a difference of $\mathrm{P}<0.05$ from NF while ${ }^{* *}$ denotes a difference of $\mathrm{P}<0.05$ from NF. 
tween $100 \mathrm{LIQ}$ and 50LIQ $(\mathrm{P}=0.0453)$. Change in $T_{r e}$ between $100 \mathrm{ICE}$ and $100 \mathrm{LIQ}$ were $0.020 \pm 0.008^{\circ} \mathrm{C} \cdot \mathrm{min}^{-1}$ and $0.022 \pm 0.007^{\circ} \mathrm{C} \cdot \mathrm{min}^{-1} ; \mathrm{P}=0.3936$, respectively with no clear differences between conditions (mean difference $14.6 \%$, $90 \% \mathrm{CI}:-12.6$ to $50.1 \%)$.

\subsection{Time to Exhaustion ( $\left.T_{\text {lim }}\right)$}

Figure 2(c), identifies differences in $T_{\text {lim }}$ between NF versus 100 ICE $(P=0.0224)$ and 50 ICE versus 100 LIQ $(\mathrm{P}=0.05)$. Time to exhaustion increased by $\sim 6 \%$ when consuming 100 ICE versus 100 LIQ, $15 \%$ between 50 ICE and 50 LIQ and 28\% between 100\% and 50\% fluid replacement. Ingesting 100 ICE compared to 50 ICE and 100 LIQ resulted in "unclear" outcomes in $T_{\text {lim }}$. Differences between 100 ICE and 50 ICE were (mean difference $18.4 \%$, 90\% CI: -45.8 to $22.9 \%$ ), 100 ICE and 100 LIQ (mean difference $8.1 \%$, $90 \%$ CI: -41.2 to 43.8\%) accordingly.

\subsection{Termination Criteria}

Across all interventions (50 trials in total), 7 trials completed the entire exercise protocol, 27 stopped voluntarily due to exhaustion and 16 reached the maximum allowable $T_{r e}$. No trials were stopped because of maximum HR. In total 43 trials were terminated due to physical exhaustion. This consisted of all NF and 50 LIQ trialsbeing terminated due to physical exhaustion, $90 \%$ of 50 ICE, 80\% of 100 LIQ and $60 \%$ of 100 ICE trials were terminated on the same criteria. During these trials no participant reached the $T_{r e}$ cut off.

Table 2 outlines mean time (min) to achieve $T_{r e}$ of $38.0^{\circ} \mathrm{C}$ and $38.5^{\circ} \mathrm{C}$. Of the 50 trials completed, three participants were exhausted before $T_{r e}$ reached $38.0^{\circ} \mathrm{C}$. Mean times were similar $(\mathrm{P}=1.000)$ between conditions except 100 LIQ and 50 LIQ $(\mathrm{P}=0.018)$. Sixteen participants were exhausted before achieving $T_{r e}$ of $38.5^{\circ} \mathrm{C}$. One participant was able to complete the 2 hour protocol without achieving a $T_{r e}$ of $38.5^{\circ} \mathrm{C}$. No differences were observed $(\mathrm{P}=0.172)$ between time to reach $38.5^{\circ} \mathrm{C}$.

\subsection{Sweat Rate}

Estimated sweat rates for each drink condition was $22 \pm 5 \mathrm{ml} \cdot \mathrm{min}^{-1}(\mathrm{NF}), 19 \pm 3 \mathrm{ml} \cdot \mathrm{min}^{-1}$ (100 ICE), $19 \pm 4$ $\mathrm{ml} \cdot \mathrm{min}^{-1}$ (50 ICE), $20 \pm 7 \mathrm{ml} \cdot \mathrm{min}^{-1}$ (100 LIQ) and $19 \pm 7 \mathrm{ml} \cdot \mathrm{min}^{-1}$ (50 LIQ). Sweat rates were not different $(\mathrm{P}=$ 0.104 ) between conditions.

\subsection{Heart Rate}

No statistical differences in HR were observed between conditions. 100 ICE produced a mean HR value of 163 \pm 12 bpm followed by 50 LIQ (167 \pm 11 bpm), 100 LIQ (169 \pm 9 bpm), NF (169 \pm 15 bpm) and 50 ICE (172 \pm 6 bpm). Although no statistical differences were measured for HR between conditions; further analysis revealed a “trivial to non-trivial” reduction in HR when comparing ingesting 100 ICE to 50 ICE (mean difference 5.7\%, 90\% CI: 0.9 to $10.8 \%$ ), and 100 ICE to 100 LIQ (3.9\% mean difference, 90\% CI: -1.2 to 9.3\%). For 50 ICE vs. 50 LIQ comparison, there was a "trivial to non-trivial” reduction in HR (mean difference 3.1\%, 90\% CI: -1.1 to $7.1 \%$ ) when ingesting 50 ICE.

Table 2. Time (min) to reach $T_{r e}$ of $38.0^{\circ} \mathrm{C}$ and $38.5^{\circ} \mathrm{C}$.

\begin{tabular}{|c|c|c|c|c|c|}
\hline & NF & 100 ICE & 50 ICE & 100 LIQ & 50 LIQ \\
\hline \multicolumn{6}{|c|}{ Time $38.0^{\circ} \mathrm{C}$} \\
\hline Avg & 27.3 & 34.1 & 28.8 & $36.0 *$ & 26.8 \\
\hline SD & 9.4 & 14.5 & 7.2 & 7.1 & 8.2 \\
\hline \multicolumn{6}{|c|}{ Time $38.5^{\circ} \mathrm{C}$} \\
\hline Avg & 37.0 & 68.5 & 60.1 & 78.3 & 42.0 \\
\hline SD & 10.6 & 33.8 & 24.5 & 15.9 & 10.4 \\
\hline
\end{tabular}

*difference from 50 LIQ $(\mathrm{P}<0.05)$. 


\section{Discussion}

It was hypothesised that replacing $100 \%$ of sweat loss with ice slurry ingestion would result in the greatest attenuation of thermal strain during exercise due to the larger cooling capacity associated with the enthalpy of fusion. However, contrary to our hypothesis, both 100 ICE and 100 LIQ provided similar physiological responses in participants as did 50 ICE compared to 50 LIQ. Complete replacement of sweat loss increased $T_{\text {lim }}$, reduced the rate of $\Delta T_{r e}$ and reduced the rate of heat stored when comparing to replacement of half sweat loss during simulated mining conditions.

Although there was an increase in $T_{\text {lim }}$ and an attenuated rise in $T_{r e}$ during exercise for both $100 \%$ sweat replacement conditions, this conflicts with the theoretical cooling capacities of the solutions calculated from sweat rates during NF. For each condition, the cooling capacities were: 100 ICE (594.2 $\pm 104.7 \mathrm{~kJ}), 50 \mathrm{ICE}$ (320 \pm $76.2 \mathrm{~kJ}), 100 \mathrm{LIQ}(179.8 \pm 42.8 \mathrm{~kJ}), 50 \mathrm{LIQ}(89.9 \pm 21.4 \mathrm{~kJ})$ and NF $(0 \mathrm{~kJ})$. The aforementioned cooling capacities were estimated from the specific heat capacities of ice and liquid water in addition to the enthalpy of fusion for the respective volumes. From the mean sweat rates measured during $\mathrm{NF}$ and a thermal transition from $-1{ }^{\circ} \mathrm{C}$ to $38^{\circ} \mathrm{C}$ for ICE and $4^{\circ} \mathrm{C}$ to $38^{\circ} \mathrm{C}$ for LIQ, the presented values were derived. Based on these cooling capacities, it was hypothesised that $\mathrm{T}_{\lim }$ and the attenuated rise in $T_{r e}$ would follow a similar trend to that of drink cooling capacities. This was contrary to what was observed. Possible explanations could be due to the thermal inertia within the body. If a large enough heat sink was ingested (i.e., 100 ICE), then this sink could affect the heat stored within the body. Reference [25] observed a similar thermal inertial phenomenon while measuring in several locations the cooling and warming gradient in a leg of beef submerged in a cold $\left(16^{\circ} \mathrm{C}\right)$ and warm water $\left(42^{\circ} \mathrm{C}\right)$ bath. He observed quicker temperature changes from the outside of the leg and slower changes within. Upon rewarming, an after-drop was noticed from the inner layers until a point where the deeper thermometers began to warm. This would suggest that a specific quantity of heat must be removed before a temperature change is observed. As the participants in the present study were not static, such as the leg of beef, the total quantity of solution provided (100\% versus 50\%) may not have been sufficient to overcome the gradient.

Our findings extend upon the work of [26], who demonstrated that cold $\left(4^{\circ} \mathrm{C}\right)$ compared to warm $\left(37^{\circ} \mathrm{C}\right) \mathrm{drink}$ administered prior to and during cycling exercise lowered mean $T_{r e}$ during exercise $\left(37.3^{\circ} \mathrm{C} \pm 0.4^{\circ} \mathrm{C}\right.$ versus $\left.38.0^{\circ} \mathrm{C} \pm 0.4^{\circ} \mathrm{C}\right)$ and extended $T_{\text {lim }}(63.8 \pm 4.3$ versus $52.0 \pm 4.1 \mathrm{~min}$; cold versus warm drink, respectively). A likely explanation for the slower rate of rise in $T_{r e}$ seen in our participants during the $100 \%$ fluid replacement conditions is the greater heat sink associated with the larger volumes of fluid ingested. The rate of rise in $T_{r e}$ was lowest and $T_{\text {lim }}$ was longest for 100 ICE and 100 LIQ conditions. It could be assumed that hydration status of the participants could account for our results; however, upon closer examination of hydration status, post exercise differences were only observed in 50\% replacement trials (Table 1). Nohydration differences were observed in NF or 100\%; rather, differences in drink quantity administered occurred. This would suggest that the results observed are due to the heat sink ingested. The heat sink increased the total capacity of heat to be stored, hence the observable slower rise in $T_{r e}$ and greater $T_{\text {lim }}$ in 100 ICE and 100 LIQ compared to 50 ICE and 50 LIQ. A reduction in work rate is often observed with an elevated body temperature [27]-[29] and could possibly explain the differences observed in $T_{\text {lim }}$ between $100 \%$ and $50 \%$ fluid replacement conditions. Indeed, the termination of exercise in the heat has been shown to coincide with a high $T_{c}$ [30]; therefore, the reduced rate of rise in $T_{r e}$ can be attributed to the cooling capacity of the larger fluid volumes. This does not however explain the similarities observed between 100 ICE and 100 LIQ. The approximate cooling capacities were $639.4 \pm 147.5 \mathrm{~kJ}$ for $100 \mathrm{ICE}$ and $180.6 \pm 41.7 \mathrm{~kJ}$ for $100 \mathrm{LIQ}$. This equates to an approximate 3.5 fold increase in cooling capacity for 100 ICE. This suggests that the additional cooling provided by the $100 \%$ fluid replacement was delivered to other regions of the body (i.e., organs) compared to 50\% fluid replacement possibly via counter current blood flow.

Reference [17] reported the consumption of $7.5 \mathrm{ml} \cdot \mathrm{kg}^{-1}$ ice-slurry resulted in a lower pre-exercise $T_{c}$, compared with ingesting cool liquid $\left(4^{\circ} \mathrm{C}\right)$. Although the study had participants ingest the solutions before exercise in a thermoneutral environment, it confirms the ice-slurry's greater cooling capacity over cool liquids of equal volumes. Additionally, $T_{\text {lim }}$ was significantly $(\mathrm{P}=0.001)$ increased during ice-slurry $(50.2 \pm 8.5$ min $)$ versus cold liquid (40.7 $\pm 7.2 \mathrm{~min})$ condition. The findings from [17] are not congruent with our observations possibly due to the fact that our participants ingested the ice-slurry while exercising and their participants ingested the iceslurry pre-exercise. Mundel and colleagues [31] administered two drink temperatures $\left(19^{\circ} \mathrm{C}\right.$ and $\left.4^{\circ} \mathrm{C}\right)$ ad libitumto subjects cycling at $65 \%$ of their peak maximal aerobic power until exhaustion. An observed increase in performance from $55 \pm 4 \mathrm{~min}$ to $62 \pm 4 \mathrm{~min}$, a $5 \mathrm{bpm}$ reduction in $\mathrm{HR}$ and $T_{r e}$ of $0.25^{\circ} \mathrm{C}$ during the second half of exercise when consuming the colder drink. Furthermore, a greater volume of fluid was consumed during the 
cold drink condition $\left(1.3 \pm 0.3 \mathrm{~L} \cdot \mathrm{h}^{-1}\right.$ vs. $1.0 \pm 0.2 \mathrm{~L} \cdot \mathrm{h}^{-1}$; P $\left.<0.05\right)$. In our investigation, although not significant, consuming a cooler beverage resulted in an increased $T_{\text {lim }}$ and lowered cardiovascular strain; a finding that mirrors Mundel and colleagues [31].

The deleterious effects of dehydration can potentially be offset by increasing evaporative heat loss [32]. However, due to low air flow conditions in an underground mine, this thermolytic avenue can become limited. While comparing fluid volume replacement on performance and hydration status in the current study, $100 \%$ sweat loss replacement resulted in increased performance. Both $100 \%$ fluid replacement conditions resulted in a slower rate of rise in $T_{r e}$, heat storage, increased $T_{\text {lim }}$, and produced higher sweating rates, compared to $50 \%$ and NF. As the fluid replacement volumes were equivalent, the thermolytic and performance based responses could be attributed to the greater availability of fluids [33], while the slight increase in performance could be attributed to the larger heat sink in the ice-slurry (cooler drink) [26].

In the present study, 100ICE had the smallest increase in HR during exercise. This smaller increase in HR, compared to the other conditions, could be attributed to the larger heat sink provided by the ingestion of the cooler ice-slurry [31]. Reducing thermal strain could decrease sweat rates and in turn preserved blood volume. Comparing changes in blood volume between 100 ICE and 100 LIQ, a "trivial to non-trivial" outcome was measured. This finding suggests a physiological benefit to ingesting 100 ICE over 100 LIQ. As previously mentioned, the range of fitness levels within the study could be a confounding factor for the absence of statistical significance. As seen in Table 1, 100ICE resulted in the smallest change in blood volume. Further support to blood volume sparing is given by similar before and after $U_{s g}$ and $U_{\text {osm }}$ values.

An alternative explanation to our findings of similar $T_{\text {lim }}$ observed between conditions are the variability in fitness levels between our participants. With standardized work intensity, those individuals with a decreased capacity to do work could have skewed the data. As the purpose of this investigation was to determine the cooling capacity during a simulated mining condition, the participant selection was appropriate. Future investigations incorporating a more homogeneous population could result in observable differences in the various physiological measurements.

Industrial best practices are focused on maintaining a core temperature below that of approximately $38.0^{\circ} \mathrm{C}$; however there are circumstances where $T_{c}$ can be $38.5^{\circ} \mathrm{C}$ [6]. Should $T_{c}$ rise above set upper limits, production is halted and the worker must rest until $T_{c}$ returns to a safer temperature. As we have shown, replacing $100 \%$ sweat loss can prolong time to achieve both $38.0^{\circ} \mathrm{C}$ and $38.5^{\circ} \mathrm{C}$ better than replacing $50 \%$ sweat loss. Although greater thermal relief can be observed by drinking 100ICE than 50ICE, participants complained of bloating while consuming the larger bolus. Such stomach discomfort may hinder production. Additionally, $100 \%$ fluid replacement is not usually practiced in industry. Therefore future investigations should examine the effect of a more practical ad libitum drinking protocol on exercise time and $T_{r e}$.

\section{Conclusion}

In conclusion, this investigation has demonstrated the ingestion of 100 ICE or 100 LIQ during exercise at rates equivalent to sweat rate can increase the $T_{\text {lim }}$, reduce the rate of heat stored, and in turn attenuate the rate of rise in rectal temperature in hot and humid conditions when compared to ingesting 50 ICE and 50 LIQ. Therefore, replacing $100 \%$ of lost fluids with either ice slurry or liquid drink will provide greater thermal relief during work in hot and humid conditions, which may be a practical and effective cooling strategy which Occupational Hygienists may wish to consider.

\section{Practitioner Summary}

This laboratory study of a heat stress intervention was conducted under simulated mining conditions experienced in Australia during summer. Partial or complete volumes of fluid lost were replaced by ice-slurry or liquid. Fatigue and heat gain outcomes were improved amongst subjects consuming ice slurry. Ice-slurry was more palatable than water.

\section{Acknowledgements}

The authors would like to thank the participants for their time and commitment and also to Edith Cowan University for their financial assistance with this project. 


\section{References}

[1] Bethea, N., Bobo, M. and Ayoub, M.M., Eds. (1980) The Physiological Response to Low Coal Mining. Proceedings of the Human Factors Society 24th Annual Meeting, Los Angeles, October, 448-452.

[2] Leithead, C. and Lind, A.R. (1964) Heat Stress and Heat Disorders. Cassell, London.

[3] Donoghue, A.M. and Bates, G.P. (2000) The Risk of Heat Exhaustion at a Deep Underground Metalliferous Mine in Relation to Surface Temperatures. Occupational Medicine, 50, 334-336. http://dx.doi.org/10.1093/occmed/50.5.334

[4] McLellan, T.M., Cheung, S.S., Latzka, W.A., Sawka, M.N., Pandolf, K.B., Millard, C.E., et al. (1999) Effects of Dehydration, Hypohydration, and Hyperhydration on Tolerance during Uncompensable Heat Stress. Canadian Journal of Applied Physiology, 24, 349-361. http://dx.doi.org/10.1139/h99-027

[5] Donoghue, A.M., Sinclair, M.J. and Bates, G.P. (2000) Heat Exhaustion in a Deep Underground Metalliferous Mine. Occupational and Environmental Medicine, 57, 165-174. http://dx.doi.org/10.1136/oem.57.3.165

[6] ISO (2004) ISO 9886, 2004, Ergonomics—Evaluation of Thermal Strain by Physiological Measurements. International Standards Organization, Geneva.

[7] NIOSH. NIOSH Publication No. 86-113. Atlanta, GA: National Institute of Occupational Health; 1986. Criteria for a Recommended Standard: Occupational Exposure to Hot Environments.

[8] Maté, J., Hardcastle, S.G., Beaulieu, F.D., Kenny, G.P. and Reardon, F.D. (2007) Exposure Limits for Work Performed in Canada’s Deep Mechanized Metal Mines. Challenges in Deep and High Stress Mining, 527-536.

[9] Corcoran, S. (2002) Why Some Workers Boil over Wearing Cooling Garments. Occupational Health \& Safety, 71, 104-106.

[10] Brake, D.J. and Bates, G.P. (2003) Fluid Losses and Hydration Status of Industrial Workers under Thermal Stress Working Extended Shifts. Occupational and Environmental Medicine, 60, 90-96. http://dx.doi.org/10.1136/oem.60.2.90

[11] Cian, C., Barraud, P.A., Melin, B. and Raphel, C. (2001) Effects of Fluid Ingestion on Cognitive Function after Heat Stress or Exercise-Induced Dehydration. International Journal of Psychophysiology, 42, 243-251. http://dx.doi.org/10.1016/S0167-8760(01)00142-8

[12] Hayes, L.D. and Morse, C.I. (2010) The Effects of Progressive Dehydration on Strength and Power: Is There a Dose Response? European Journal of Applied Physiology, 108, 701-707. http://dx.doi.org/10.1007/s00421-009-1288-y

[13] Pitts, G.C., Johnson, R.E. and Consolazio, C.C. (1944) Work in the Heat as Affected by Intake of Water, Salt and Glucose. American Journal of Physiology, 142, 253-259.

[14] McConell, G.K., Burge, C.M., Skinner, S.L. and Hargreaves, M. (1997) Influence of Ingested Fluid Volume on Physiological Responses during Prolonged Exercise. Acta Physiologica Scandinavica, 160, 149-156. http://dx.doi.org/10.1046/j.1365-201X.1997.00139.x

[15] Murray, S.R., Michael, T.J. and McClellan, P.D. (1995) The Influence of Fluid Replacement Rate on Heart Rate and RPE During Exercise in Hot, Humid Environment. Journal of Strength and Conditioning Research, 9, 251-254.

[16] Gisolfi, C.V. and Copping, J.R. (1974) Thermal Effects of Prolonged Treadmill Exercise in the Heat. Medicine and Science in Sports and Exercise, 6, 108-113. http://dx.doi.org/10.1249/00005768-197400620-00019

[17] Siegel, R., Mate, J., Brearley, M.B., Watson, G., Nosaka, K. and Laursen, P.B. (2010) Ice Slurry Ingestion Increases Core Temperature Capacity and Running Time in the Heat. Medicine \& Science in Sports \& Exercise, 42, 717-725. http://dx.doi.org/10.1249/MSS.0b013e3181bf257a

[18] Ramanathan, N.L. (1964) A New Weighting System for Mean Surface Temperature of the Human Body. Journal of Applied Physiology, 19, 531-533.

[19] ISO, ISO 7243 (1989) Hot Environments-Estimation of Heat Stress on Working Man, Based on the WBGT-Index (Wet Bulb Globe Temperature). International Standards Organization, Geneva.

[20] Latzka, W.A., Sawka, M.N., Montain, S.J., Skrinar, G.S., Fielding, R.A., Matott, R.P., et al. (1998) Hyperhydration: Tolerance and Cardiovascular Effects during Uncompensable Exercise-Heat Stress. Journal of Applied Physiology, 84, 1858-1864.

[21] Popowski, L.A., Oppliger, R.A., Patrick Lambert, G., Johnson, R.F., Kim Johnson, A. and Gisolf, C.V. (2001) Blood and Urinary Measures of Hydration Status during Progressive Acute Dehydration. Medicine \& Science in Sports \& Exercise, 33, 747-753. http://dx.doi.org/10.1097/00005768-200105000-00011

[22] Dill, D.B. and Costill, D.L. (1974) Calculation of Percentage Changes in Volumes of Blood, Plasma, and Red Cells in Dehydration. Journal of Applied Physiology, 37, 247-248.

[23] Batterham, A.M. and Hopkins, W.G. (2006) Making Meaningful Inferences about Magnitudes. International Journal of Sports Physiology and Performance, 1, 50-57. 
[24] Hopkins, W.G., Marshall, S.W., Batterham, A.M. and Hanin, J. (2009) Progressive Statistics for Studies in Sports Medicine and Exercise Science. Medicine \& Science in Sports \& Exercise, 41, 3-13. http://dx.doi.org/10.1249/MSS.0b013e31818cb278

[25] Webb, P. (1985) After Drop of Body Temperature during Rewarming: An Alternative Explanation. Journal of Applied Physiology, 60, 385-390.

[26] Lee, J.K., Shirreffs, S.M. and Maughan, R.J. (2008) Cold Drink Ingestion Improves Exercise Endurance Capacity in the Heat. Medicine \& Science in Sports \& Exercise, 40, 1637-1644. http://dx.doi.org/10.1249/MSS.0b013e318178465d

[27] Caputa, M., Feistkorn, G. and Jessen, C. (1986) Effects of Brain and Trunk Temperatures on Exercise Performance in Goats. Pflügers Archiv: European Journal of Physiology, 406, 184-189. http://dx.doi.org/10.1007/BF00586681

[28] Tucker, R., Marle, T., Lambert, E.V. and Noakes, T.D. (2006) The Rate of Heat Storage Mediates an Anticipatory Reduction in Exercise Intensity during Cycling at a Fixed Rating of Perceived Exertion. The Journal of Physiology, 574, 905-915. http://dx.doi.org/10.1113/jphysiol.2005.101733

[29] Thomas, M.M., Cheung, S.S., Elder, G.C. and Sleivert, G.G. (2006) Voluntary Muscle Activation Is Impaired by Core Temperature Rather Than Local Muscle Temperature. Journal of Applied Physiology, 100, 1361-1369. http://dx.doi.org/10.1152/japplphysiol.00945.2005

[30] Gonzalez-Alonso, J., Teller, C., Andersen, S.L., Jensen, F.B., Hyldig, T. and Nielsen, B. (1999) Influence of Body Temperature on the Development of Fatigue during Prolonged Exercise in the Heat. Journal of Applied Physiology, 86, 1032-1039.

[31] Mundel, T., King, J., Collacott, E. and Jones, D.A. (2006) Drink Temperature Influences Fluid Intake and Endurance Capacity in Men during Exercise in a Hot, Dry Environment. Experimental Physiology, 91, 925-933. http://dx.doi.org/10.1113/expphysiol.2006.034223

[32] Saunders, A.G., Dugas, J.P., Tucker, R., Lambert, M.I. and Noakes, T.D. (2005) The Effects of Different Air Velocities on Heat Storage and Body Temperature in Humans Cycling in a Hot, Humid Environment. Acta Physiologica Scandinavica, 183, 241-255. http://dx.doi.org/10.1111/j.1365-201X.2004.01400.X

[33] Sawka, M.N., Burke, L.M., Eichner, E.R., Maughan, R.J., Montain, S.J. and Stachenfeld, N.S. (2007) American College of Sports Medicine Position Stand. Exercise and Fluid Replacement. Medicine \& Science in Sports \& Exercise, 39, 377-390. http://dx.doi.org/10.1249/mss.0b013e31802ca597 